\title{
Causes and Effects of Mining Subsidence.
}

\author{
By Sir Richard Redmayne, K.C.B.
}

THE final report of the Royal Commission 1 on Mining Subsidence, ${ }^{1}$ appointed on Mar. 17,1924 , has recently been published. The Commission was asked to inquire into the operation of the law relating to support of the surface underlying minerals, the extent and gravity ff tor damage caused by subsidence owing to the etracetion of minerals, and to report as to what steps should be taken by legislation or otherwise to remedy equitably the hardships that may arise in existing conditions-a wide and controversial field - and Lord Blanesborough, the chairman, is to be congratulated, not only in securing unanimity, but also in having presented an admirable and lucid report.

The subjects of the report, which is concerned almost exclusively with the coal-mining aspect of the case as "the extraction of other minerals presents in this country no feature sufficiently outstanding to call for separate attention" at their hand, are considered under convenient heads which allow of the matter being easily and quickly digested. To the technical expert, perhaps, the matter dealt with under the earlier headings is the most interesting, namely-the physical aspects of subsidence, and the uncertainty of its incidence, as well as the definition of the problem before the Commission, the legal position. The definition given of subsidence is worth reproduction in view of some of the decisions that have been arrived at in the Law Courts. "Where," says the report, " a seam of mineral is completely extracted the unsupported roof falls. If the overlying beds consist of comparatively soft strata, these will bend down gradually and fill the void almost completely, and the superincumbent beds will come down in turn until the subsidence reaches the surface. In every case the descent of the superincumbent strata is accompanied by more or less fracturing and, therefore, by an incrcase in the volume of the strata thus let down. It follows that the surface subsidence is never equal to the thickness of the mincral extracted."

The full meaning which is meant to be conveyed by the words, "where a seam of mineral is completely extracted," is not clear. Literally interpreted, they would mean that the area of extraction involved would extend over the whole coalficld. 'The sentence should have read, "where a ccrtain area of a seam of mineral is completely extracted." What that area has to be before subsidence commences has been a source of much argument in the Law Courts and elsewhere, is subject to variation, and is largely determined by circumstances, such as the thickness of seam worked, depth of the seam from the surface, inclination and nature of the strata overlying the seam, and the presence of faults. To maintain, as was asserted in a recent classic law case, that, on

I Second and Final Report of the Royal Commission on Mining Subsidence. Pp. 68, (Tundon: H.M, Stalionery Office, 1027.) Price 18, 3d. net.

No. 3026, VoL. 120] extraction of a coal-seam (only very small temporary support being left by odd pieces of coal which were left in the process of working), the roof consisting of a strong bed of sandstone, 45 fulf bend, and eventually a period of quiescence b) attained without the roof and floor meeting, is a most crroneous view, but one more widely held than is generally supposed. It is pleasing, therefore, to find the Commission upholding the correct view and stating that the roof in such a case will break into comparatively large blocks which, piling up irregularly on each other, afford at the outset a certain measure of support to the overlying beds. The presence of these beds gradually crushing down partly reconsolidates the broken blocks, and in this way the subsidence ultimately reaches the surface. The movement, too, continues longer, and the total amount of surface subsidence is less than when the superincumbent strata consist mainly of softer and more plastic rocks.

The Commission arrives at the conclusion that the amount of subsidence is not quantifiable and " cannot be predicted with any accuracy, even when all the conditions are tolerably well as. certained." I should hesitate to be so positive as this. Given the thickness of the seam, the method of working practised, the nature and thickness inclination of the superincumbent strata, it should be possible to arrive at a fairly close approximation, not only as to the amount, but also the period of the subsidence consequent upon extraction of the underlying mineral.

The "problem of damage" from subsidence, as regarded by the Commission, can perhaps be epitomised thus :

1. It may be better in the national interest in some cases to leave minerals unworked than to work them, for example, in such a case as where lowering the surface would cause the land to become a swamp.

2. The detcrmination of cases in which a remedy is called for where damage has been done to the surface and building, etc., where the owners have no claim for redress or compensation under existing conditions.

Most pcople are under the impression that the right of surface support is universal, but such is not the case. The right of support to the surface may have been lost through severance at some time of the ownership of the minerals from the owncrship of the surface, but "unless the power to let down the surface be found in the instrument of severance," said Lord Swinfen (M.R. 1915, $1 \mathrm{ch} .264)$, "and unless the power to let down the surface be found there expressly or by necessary implication, the common law of right of surface owner to support will prevail." Conveyancers in settling instruments of severance have devised provisions unambiguous in respect of power to 
let down the surface, so there exists to-day in Great Britain a class of surface owner who has no right of support of the surface. Again, the introduction of the Mines (Working Facilities and Support) Act, 1923, excellent measure though it is, has erected machinery for the purpose of enabling minerals to be worked irrespective, speaking generally, of the resulting effect upon specific surface property, and notwithstanding that, apart from the Act, the surface is entitled absolutely to support. In such a case the owner is entitled to, but he must be content with, pecuniary compensation.

The Commission recommends that private owners or occupiers of dwelling-houses of an annual value not exceeding $\mathfrak{E 4 0}$ be entitled to compensation for damage to property arising from subsidence due to the extraction of adjacent minerals, such damage being manifest at the time of or subsequent to the passing of an Act allowing compensation, the compensation to be recoverable from any person who has worked the minerals under or adjacent to the house, which impresses one as being a wise and fair solution. The statement of the legal position, and the arguments which have influenced the Commission in arriving at this decision, are set out with admirable clearness and precision, and should be read with care by all of those interested in the subject, whether mining engineers, local authorities, lawyers, or property owners.

The remarks under the heading "Methods of Mitigating Subsidence Damage" are particularly interesting to the mining engineer. Upon this aspect of the matter the report considers three suggestions, namely :

(a) The hydraulic stowage of the excavated areas and more scientific methods of mining.

(b) The scientific lay-out of the surface; and

(c) Precautions possible in the construction of surface buildings.

As to the first, the conclusion is reached that the universal adoption in Great Britain of the filling of the mine wastes with débris under hydraulic pressure - a system so largely practised in the Pas de Calais, the Westphalian, and some other continental coalfields-is impracticable, chiefly because of the cost, a conclusion which was also arrived at a few years ago, for a similar reason, by the Government Committee on Spontaneous Combustion in Mines, of which the present writer was chairman. Except in a very few areas, such as South Staffordshire, where the circumstances in respect of the presence of the necessary material and underground conditions are more favourable to its introduction-at Motherwell, in Scotland, where it is being advantageously employed, the cost is estimated at $1 s .3 d$. per ton of coal raised.

Under a system of longwall working with regular advance of an even face and close and systematic packing of the goaf or waste, the subsidence resulting from the extraction of the coal is less than under the irregular working of coal. The longwall system is not, however, always practicable, for example, in the case of a very thick seam.
The disadvantage of erecting houses in long terraces, and the advantage of building them in blocks of two or four instead, is pointed out. "The more scientific 'zoning' and development of the surface according to current conceptions of Town and Regional Planning should also do much to mitigate the damage caused by subsidence."

Under the third suggestion the Commissioners are impressed by the view expressed by Dr. Faber, who gave evidence before them, namely, that ordinary brick buildings would suffer much less from subsidence if lime mortar were replaced by cement mortar, the tensile strength of the latter being many times greater, the increase in cost not amounting to more than two or three per cent. The ordinary miners' cottage, he considered, would be perfectly safe "if built of ordinary brickwork with cement mortar on a properly constructed ferro-concrete raft."

The interests involved are classified by the Commission under three heads, namely: (1) The National Interest; (2) the Local Authorities; (3) Private Owners.

Under the first the matter involved has already been touched upon, namelly, the possibility in some cases of the surface being rendered valueless by its being lowered. The Commission has the Doncaster area chiefly in mind, and in accordance with the recommendations made prior to the issue of this, the final report, a Commission of Inquiry has been set up.

The interests of local authorities in respect of possibility of subsidence are chiefly concerned with waterworks and sewage works. The Public Utility Companies, the Statutory Tramways Companies, and the Statutory Gas and Electricity Companies are likewise involved. Under the Railway Clauses Act, 1845 , it is assumed that subsidence only takes place, more or less vertically, above the mineral workings - an assumption which all mining men now know to be erroneous-and a limit of forty yards was imposed as the distance beyond which the workings should not approach the thing to be supported. It was considered that the forty-yards' limit gave ample support from subjacent minerals.

The special code of the Support of Sewers Act is a modification of the code in the Waterworks Clauses Act, 1847, the main difference being that the Local Authority may specify any distance within which they require the minerals to be left unworked. The matter in respect of railways has been modified by the Mines (Working Facilities and Support) Act, 1923, the statutory distance being enlarged to one-half the depth of the seam from the surface-though this is not a 'scientific' distance - and provides payment by the mineowner of partial compensation for damage caused by his workings within the statutory distance in cases where the right to purchase support has not been exercised by the railway company. The Commissioners are of the opinion that the right given under Part 1 of the Mines (Working Facilities and Support) Act, 1923, to prohibit and 
restrict the working of minerals should be extended to Local Authorities and Statutory Undertakings, which seems to be only right. It is to be hoped, however, that a more scientifically defined limitation in regard to the extent of lateral support to be left from subjacent minerals will be devised than that existing in respect of railways.

The exigencies of space prohibit a longer dissertation on this most valuable and interesting report, which is a model of conciseness and clarity, and should be widely and carefully read.

\section{The Chemistry of Hormones.}

THE British Associng the advantage over 1 a number of Decialist societies in that it brings togthemingstigators in different branches of science $Y$ it hakes good use of this advantage in the joint meetings of cognate sections and by discussions on the border line between two sciences. In framing his programme for the Leeds meeting, the recorder of Section B (Chemistry) must have had these advantages in view, for he secured contributions from a number of physiologists to a valuable discussion on Sept. 5 on the chemistry of hormones.

In opening the discussion, Prof. G. Barger (Edinburgh) began by explaining what is meant by a hormone. In contradistinction to the longknown method of stimulation by a nervous impulse, Bayliss and Starling first recognised, in the case of secretin, that a stimulus may also be brought about by a chemical messenger or hormone, set free in one organ and travelling through the blood stream to another organ which is then excited to activity. Thus the hormones are highly active and highly specific drugs which the body elaborates for its own uses. The preparation and study of the hormones is thereforc of the greatest importance to medicine, since they may produce effects quite unobtainable by the ordinary vegetable or synthetic drugs. The recent introduction of insulin in the treatment of diabetes is a case in point.

With the aid of lantern slides, Prof. Barger illustrated the course of development of our knowledge by reference to the two hormones which have so far been synthesised, adrenaline and thyroxine. There is first the recognition by the clinician or physiologist of the importance of the organ producing the hormone. In the two cases mentioned, this was followed by the discovery in it of some chemical peculiarity (chromogen in the adrenal gland, iodine in the thyroid). The biochemist then attempts the isolation of the active substance in a state of purity, and when this has been achieved, the organic chemist can investigate the molecular structure of the hormone and finally synthesise it; when the physiologist certifies the synthetic product to have the same degree of activity as the natural substance, some degree of finality has been reached.

For this reason Prof. Barger did not deal with the constitution and synthesis of adrenaline and thyroxine as choses jugees, but focussed attention on the crystalline substance of high molecular weight, obtained recently from commercial insulin by Abel and his co-workers, and having in a high degrec the physiological activity characteristic of this hormone. The substance can be recrystallised and retains its activity ; indeed, the residue loft on evaporation of the mother liquor is, weight for weight, much less active than the crystals. This would constitute a prima facie claim that insulin has thus been obtained in a state of chemical purity, but Abel, aware of the pitfalls which beset investigations of this kind, himself suggests the alternative, that the crystals may carry down "an unknown substance of almost unbelievable potency." The carrying down of insulin by a crystalline precipitate of a much simpler substance, benzoic acid, formed in its solution, has actually been used in the manufacture of insulin.

Prof. Barger directed attention to the analogous difficulty in appraising the recent work of Jansen and Donath, who described the isolation of the enormously active vitamin from rice polishings. These authors crystallised a hydrochloride from acetone and alcohol, converted it into the crystalline picrolonate and gold salt, and passed back from these to the original hydrochloride without loss of activity. Here adsorption would seem to be excluded. In the case of insulin the substance can only be crystallised from water in the same way as it is formed originally, i.e. by the careful addition of ammonia to a highly buffered solution.

The subsequent discussion showed that this method did not entirely satisfy organic chemists ; Prof. J. L. Simonsen compared it to the precipitation of barium sulphate; Prof. J. Mellanby pointed out the analogy to the crystallisation of proteins. A lettcr was read from Mr. F. H. Carr (unfortunately prevented from being present); he had carried out the crystallisation according to Abel's directions but found that the crystals were only one and a half times as active as the starting material (the ordinary commercial product of British Drug Houses, Ltd.). Others have also considered that the low potency of Abel's crystalline substance raises doubts as to its purity. This is, however, only an argument drawn from analogy; pure insulin may be less active than other hormones, and the only ways of settling the matter would seem to be, either to get the same crystals with a much smaller potency, or to synthesise them; the latter would be a formidable undertaking.

Prof. Barger ended by putting forward a theory of the action of adrenaline. and related amines, based on their adsorption by lecithin. He imagined the amino group of the hormone to be attracted by the phosphoric acid residue and the residual affinity of the acidic phenolic nucleus by the basic choline grouping; this would explain the optimal length of the side chain of two carbon atoms, the favourable effect of a phenolic hydroxyl, etc.

No. 3026, VoL. 120] 